\title{
Current state of theophylline in asthma
}

Until about 1975 theophylline was used in this country for the treatment of asthma almost exclusively as intravenous aminophylline. With the introduction of oral preparations theophylline came onto the market to compete with the beta agonists, sodium cromoglycate and beclomethasone. Their introduction was also coincident with the age of the clinical trial-some would say the age of the poor clinical trial-and theophylline has been compared with almost every other drug for asthma in what seems to be every possible permutation. Those who have escaped involvement in the trials will not have escaped the marketing. In this country there are no fewer than five slow release, two liquid, and two tablet preparations suitable for children. As not all are $100 \%$ theophylline dosage, when translated into patient oriented language of mls and pills, becomes an exercise of memory and arithmetic.

\section{Does theophylline work?}

There is no doubt that theophylline is an efficient bronchodilator, but how it works is unknown. It has little effect on bronchial responsiveness to nonspecific agents such as histamine ${ }^{1}$ and is only moderately effective in blocking exercise induced bronchospasm. ${ }^{2}$ In patients with asthma improvement in lung function is significant when serum concentrations reach $5 \mu \mathrm{g} / \mathrm{ml}$ and correlates with the logarithm of concentrations between 5 and 20 $\mu \mathrm{g} / \mathrm{ml}^{3}{ }^{3}$ The response is variable between individuals.

\section{How does theophylline compare with other drugs?}

Studies that have compared theophylline with the beta agonists have produced conflicting results. One reason for this is the different dosages, duration of action, and routes of administration of the preparations of beta agonists used. The impression is that they compare favourably. Either would be suitable when the continuous treatment of asthma with oral drugs is considered most appropriate-in very young children, for example. ${ }^{4}$ Certainly, they have an additive effect, a property made use of in the hospital management of acute asthma but that can also be exploited in the prevention and management of acute wheezy episodes as home. It seems sensible to start a beta agonist and add theophylline if necessary at the beginning of an upper respiratory tract infection in a child who is likely to become very wheezy. Theophylline also compares very well with cromoglycate $^{5}$ but is not as good as beclomethasone. ${ }^{6}$ In some patients with particularly troublesome asthma the addition of theophylline to beclomethasone will improve control. Many patients may be satisfactorily controlled during the day on whatever treatment but are still disturbed by nocturnal symptoms and it is for these that a slow release preparation taken before bed may well be beneficial. $^{7}$

\section{What value is there in monitoring serum concentrations?}

Much has been written about this vexed subject. Blood concentrations are easy to measure, and recently there has been introduced a fingerprick method for bedside use (Acculevel, Syva). This is likely to be of most use in planning aminophylline treatment in patients with acute asthma who have already taken theophylline. Unfortunately, salivary concentrations, under normal circumstances of collection, do not correlate well enough with serum concentrations to be of clinical value. ${ }^{8}$

Pharmacodynamic uncertainties. Absorption and bioavailability of some commonly used preparations are severely affected by food in the stomach, ${ }^{9}$ and it is possible that factors that affect gastiic emptying, such as exercise, also affect absorption. The interpatient variation in half life- $1.5-10.5$ hours-is well known. ${ }^{10}$ There is also appreciable intrapatient variation over a period of one to nine months, ${ }^{11}$ but how much variation there is from day to day in the paediatric outpatient is unknown. There is evidence in both adults and children that timed serum concentrations during the elimination phase may vary considerably. ${ }^{12}{ }^{13}$ In addition, elimination rates are prolonged by many other factors, among them the presence of viral infections-notably, influenza-and treatment with erythromycin. ${ }^{14}$

Thus it seems that single measurements of serum theophylline are of little value. Even a carefully timed profile of concentrations measured in hospital may not accurately reflect the day to day profile in a 
child who may not have a reproducible day to day lifestyle.

When should a profile of concentrations be measured? Dosages of commonly available preparations that are most likely to put patients' concentrations within the correct range have been worked out. ${ }^{15}$ On such dosages concentrations much in excess of $20 \mu \mathrm{g} / \mathrm{ml}$ are unlikely under normal circumstances and in excess of $35 \mu \mathrm{g} / \mathrm{ml}$, above which life threatening side effects can occur, quite improbable. Patients whose asthma is satisfactorily controlled in this way-that is, without a profile of blood concentrations - should be made aware of situations when their concentrations will possibly rise and cause nausea-for example, during an upper respiratory tract infection.

If the dosage does not produce a therapeutic result - that is, the asthma is not controlled-the clinician has two choices: he can either admit the child for a profile, remembering the difficulties in interpreting such a profile, and increase the dosage if necessary (after which he should logically do another profile) or he can simply change the drug. Patients with severe asthma in whom manipulation of drugs has failed to effect adequate control are the most likely candidates for the 'tailoring' of theophylline dosage. Ideally, this should be done under conditions of diet and activity most resembling those of everyday life.

\section{Side effects}

Severe toxicity in children, with convulsions, coma, and haemorrhage, which can clearly be ascribed to theophylline, seems to occur only when the usual dose has been exceeded or when aminophylline has been given in addition.

It is the clinical impression that theophylline, even when concentrations are below $20 \mu \mathrm{g} / \mathrm{ml}$, is associated with nausea and vomiting. In a double blind study comparing cromoglycate with theophylline where patients were informed beforehand what side effects might occur $^{5}$ there was surprisingly little difference between the two groups in the reporting of side effects usually attributable to theophylline, although it has to be admitted that the number of patients was very small. What is more worrying than nausea or vomiting, which may well stop the patient taking the drug or the clinician prescribing it, is the risk of side effects such as changes in concentration and sleep disturbances, which may interfere with schooling and which cannot so easily be attributed to the drug. ${ }^{16}$ As theophylline is a drug closely related to caffeine, which has well described psychotoxic side effects in susceptible subjects, it seems on a pharmacological basis that anxieties are not unreasonable. ${ }^{17}$ It would seem to be a matter of some importance, if theophylline is to continue to be widely prescribed, that the possibility of this side effect is more carefully examined. The problem is that designing a trial to evaluate such side effects properly would be likely to be a very difficult undertaking.

\section{Conclusion}

Although theophylline is an invaluable bronchodilator in the management of acute asthma, it has many limitations when considered for use in the day to day management of continuous asthma. Single measurements of serum theophylline are of limited value and it would seem that the tailoring of dosage may not be as straightforward as previously supposed. There seems to be sufficient concern about the incidence of side effects to suggest that theophylline should not be the drug of first choice for the management of continuous asthma when other less troublesome drugs are available. Theophylline does, however, have a clear place as a supplement to other drugs in the management of patients with severe asthma and in the management of nocturnal asthma when symptoms cannot be otherwise controlled.

\section{References}

${ }^{1}$ Levene S, McKenzie SA. Protective effect of theophylline against histamine induced bronchial hyperreactivity. $\mathrm{Br} \mathrm{J} \mathrm{Clin}$ Pharmacol 1986;21:445-9.

${ }^{2}$ Pollock J, Kiechel F, Cooper D, Weinberger M. Relationship of serum theophylline concentration to inhibition of exerciseinduced bronchospasm and comparison with cromolyn. Pediatrics 1977;60:840-4.

${ }^{3}$ Mitenko PA, Ogilvie RI. Rational intravenous doses of theophylline. N Engl J Med 1973;289:600-4.

${ }^{4}$ Groggins RC, Lenney W, Milner AD, Stokes GM. Efficacy of orally administered salbutamol and theophylline in pre-school children with asthma. Arch Dis Child 1980;55:204-6.

5 Furakawa CT, Shapiro GG, Bierman W, et al. A double-blind study comparing the effectiveness of cromolyn sodium and sustained-release theophylline in childhood asthma. Pediatrics 1984;74:453-9.

${ }^{6}$ Edmunds AT, McKenzie SA, Baillie E, Tooley M, Godfrey S. A comparison of oral choline theophyllinate and beclomethasone in severe perennial asthma in children. $\mathrm{Br} J$ Dis Chest 1979;73:149-56.

7 Levene S, McKenzie SA. Once daily theophylline in childhood asthma. Br J Dis Chest 1986;80:66-71.

${ }^{8}$ Rylance GW, Beswick DT. Cullen RE, Roberts DGV. Reevaluation of saliva for monitoring theophylline concentrations. Arch Dis Child 1985;60:66-8.

${ }^{9}$ Pederson S, Moller-Petersen J. Erratic absorption of a slowrelease theophylline sprinkle product. Pediatrics 1984;74:534-8.

10 Ellis EF, Koysooko R, Levy G. Pharmacokinetics of theophylline in children with asthma. Pediatrics 1976;58:542-7.

"Walson PD, Strunk RG, Taussig LM. Intrapatient variability in theophylline kinetics. J Pediatr 1977;91:321-4. 
12 Taylor DR, Kinney CD, McDevitt DG. Patient compliance with oral theophylline therapy. Br J Clin Pharmacol 1984;17:15-20.

13 Beswick DT, Cullen RE, Rylance GW. Theophylline dose prediction. Arch Dis Child 1984;59:758-61.

14 Szefler SJ. Practical considerations in the safe and effective use of theophylline. Pediatr Clin North Am 1983;30:943-54.

15 McKenzie SA, Baillie E. Serum theophylline levels in asthmatic children after oral administration of two slow-release theophylline preparations. Arch Dis Child 1978;53:943-6.

${ }^{16}$ Furakawa CT, Shapiro GG, Du Hamel T, et al. Learning and behaviour problems associated with theophylline therapy. Lancet 1984 ; : 621 .

${ }^{17}$ Sattin A. Behavioural problems in children taking theophylline. Lancet $1984 ; \mathrm{i} ; 958$.

Sheila McKenzie, Rush Green Hospital, Romford, Essex 